PAEDIATRIC LESSONS FROM THE PAST

\title{
Tracing Sydenham's chorea: historical documents from a British paediatric hospital
}

\author{
D Martino, A Tanner, G Defazio, A J Church, K P Bhatia, G Giovannoni, R C Dale
}

Arch Dis Child 2005;90:507-511. doi: 10.1136/adc.2004.057679

Sydenham's chorea (SC) became a well defined nosological entity only during the second half of the nineteenth century. Such progress was promoted by the availability of large clinical series provided by newly founded paediatric hospitals. This paper analyses the demographic and clinical features of patients with chorea admitted to the first British paediatric hospital (the Hospital for Sick Children, Great Ormond Street, London) between 1852 and 1936. The seasonal and demographic characteristics of SC during this time appear strikingly similar to those observed today, and witness the introduction of modern "statistically averaging" techniques in the approach to complex paediatric syndromes. Great Ormond Street (GOS) hospital case notes provide detailed descriptions of the "typical cases" of SC, and show that British physicians working in the early age of paediatric hospitals succeeded in recognising the most distinctive clinical features of this fascinating condition.

See end of article for authors' affiliations

Correspondence to: Dr D Martino, Department of Neurological and Psychiatric Sciences, University of Bari, Piazza Giulio Cesare, 1170124 Bari, Italy; davidemartino@virgilio.it

Accepted 15 October 2004
$\mathrm{T}$ hroughout the nineteenth century the term "chorea" referred to an ill-defined spectrum of hyperkinesias, including those recognised today as chorea, tics, dystonia, or myoclonus. William Osler started his monography on chorea ${ }^{1}$ stating that "in the whole range of medical terminology there is no such olla podrida* as Chorea, which for a century has served as a sort of nosological pot into which authors have cast indiscriminately affections characterised by irregular, purposeless movements".

Sydenham's chorea (SC), a frequent cause of paediatric acute chorea, is a major manifestation of rheumatic fever (RF). ${ }^{2}$ The association of chorea with rheumatism was first reported in $1802,{ }^{3}$ and confirmed in the following decades by several French and English authors. ${ }^{4-9}$ The inclusion of chorea under the rheumatic umbrella helped discriminate SC from other "choreic" syndromes.

British paediatric hospitals' documents help us to understand how SC was perceived in the second half of the 19th century. Physicians working in early children's hospitals recognised new clinical syndromes through the definition of "typical clinical cases". ${ }^{10}$ Complex multi-systemic diseases, such as RF, were categorised only after the observation of large, hospital based series. Therefore, paediatric hospitals gradually

"Spanish for "miscellanea". became an important setting for the application of a modern "statistical averaging" technique to paediatric syndromes. Historical authorities in paediatrics, such as WB Cheadle (fig 1) and O Sturges (fig 2), worked at the Hospital for Sick Children, Great Ormond Street, London (the first British paediatric hospital, fig 3), and their clinical notes help to understand how the typical case of SC was defined.

We report the experience of the GOS hospital in acute chorea in the first 90 years of history of this institution.

\section{METHODS}

We consulted the Annual Reports of the Hospital for Sick Children, GOS, London (today Great Ormond Street Hospital for Children NHS Trust) from 1852 to 1936, available at the hospital Archives. ${ }^{11}$ This Archive has recently been computerised, allowing data analysis. The annual number of cases with a diagnosis of chorea (or St Vitus's Dance) and rheumatism on discharge were recorded. ${ }^{11}$ Data on age, gender, month of admission, and number of relapses in the 1548 patients who received a first diagnosis of chorea from 1852 to 1895 were collected. Finally, we reviewed the available clinical notes (about 200) of choreic patients dated between 1852 and 1936. Most of these notes had been stored for scientific purposes by the consultants themselves. We could not therefore undertake a systematic review of their clinical features, given the uncertainty of the original criteria in case selection. We present here two cases, which illustrate the perception of SC in the early age of paediatric hospitals.

\section{HISTORICAL DEMOGRAPHIC ANALYSIS}

Between 1860 and 1900 the proportion of choreic patients ranged between $5 \%$ and $7 \%$ of the total number of patients admitted (mean per year, 1003), whereas from 1900 to 1936 it was constantly below 4\% (mean per year, 4161). Chorea was the fourth most frequent cause of admission between 1860 and 1900, and in the 1880 s temporarily became the second most frequent diagnosis among inpatients. Contemporary articles report a homogeneous distribution of paediatric chorea all over the country. ${ }^{12}$ However, since many choreic children were "cured" at home, ${ }^{13}$ the hospital based rates probably underestimate the incidence of chorea in the general paediatric population.

Abbreviations: GOS, Great Ormond Street; RF, rheumatic fever; SC, Sydenham's chorea 


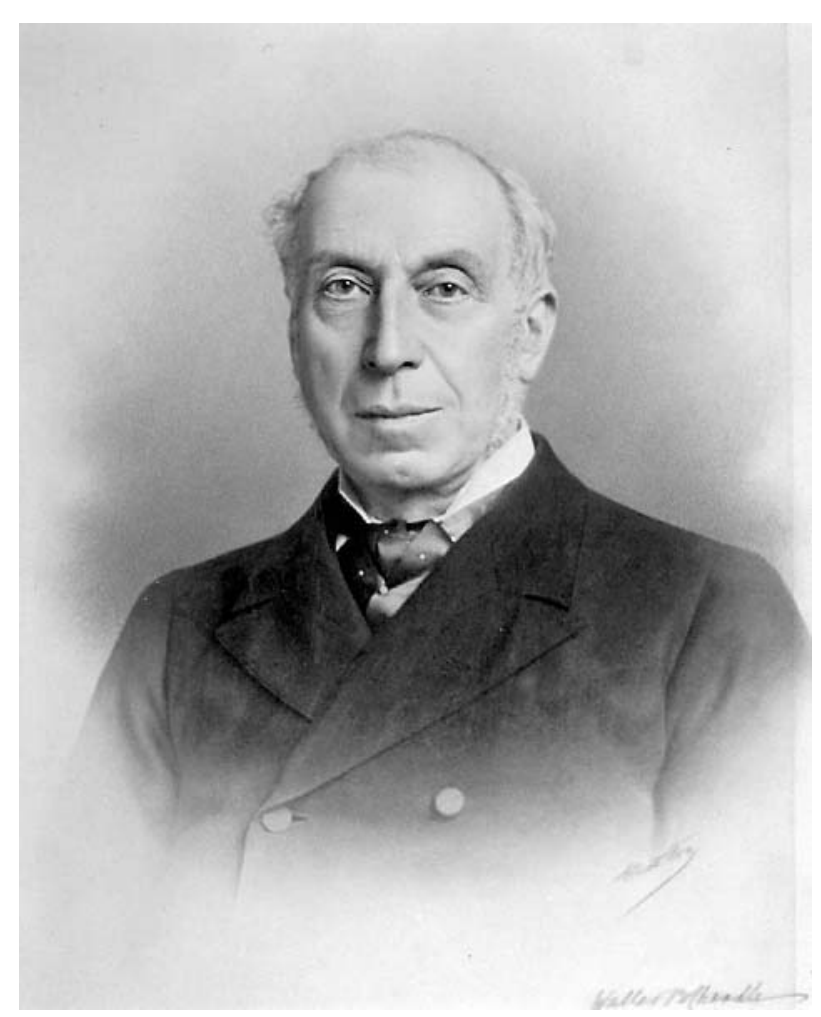

Figure 1 William Butler Cheadle (1835-1910). The photograph was kindly provided by the Museum and Archives of the Great Ormond Street Hospital, London.

The annual absolute number of choreic inpatients fluctuated, peaking approximately every 3.5 years (fig 4). The diagnosis of rheumatism (rheumatic fever) showed similar fluctuations (fig 4), with a period of approximately three years, in relative synchrony with chorea.

The fluctuating course of admissions might have several explanations. First, it might mirror the changing distribution of the rheumatogenic strains of Streptococcus pyogenes in the population. Moreover, the number of choreic patients admitted throughout the second half of the 19th century increased progressively. This was related to the increasing number of total admissions throughout this period, secondary to the growing favour encountered by paediatric hospitals. ${ }^{14}$ Also, in order to maintain encouraging healthcare figures, managers and physicians might have facilitated the admission of chorea patients, due to the benign course and the frequently favourable outcome. ${ }^{14}$

A higher number of cases were admitted during the colder months (fig 5), consistent with the reference epidemiological report on chorea at the end of the century. ${ }^{1}$ In the 1950s and 1960s the highest frequency of chorea was recorded during the winter months in several Northern and Central European countries. ${ }^{15} 16$ Interestingly, the incidence of rheumatism among GOS inpatients peaked in October, preceding chorea by approximately two months (fig 5). This is consistent with the current knowledge that most of the RF symptoms appear about 10 days after the streptococcal infection, whereas SC occurs typically 2-3 months after infection.

More than $80 \%$ of choreic patients were aged between 7 and 11 years (mean 9.2). Due to a referral bias, this age may be falsely low. Indeed, the British Medical Association (1887) reported the peak age between 11 and 15 years. ${ }^{12}$ In the present series, the female:male ratio was 2.7 , in accordance with the general choreic population of Britain towards the end of the 1800s. ${ }^{12}$ Interestingly, in children below age 7, the female preponderance is less manifest. This was observed

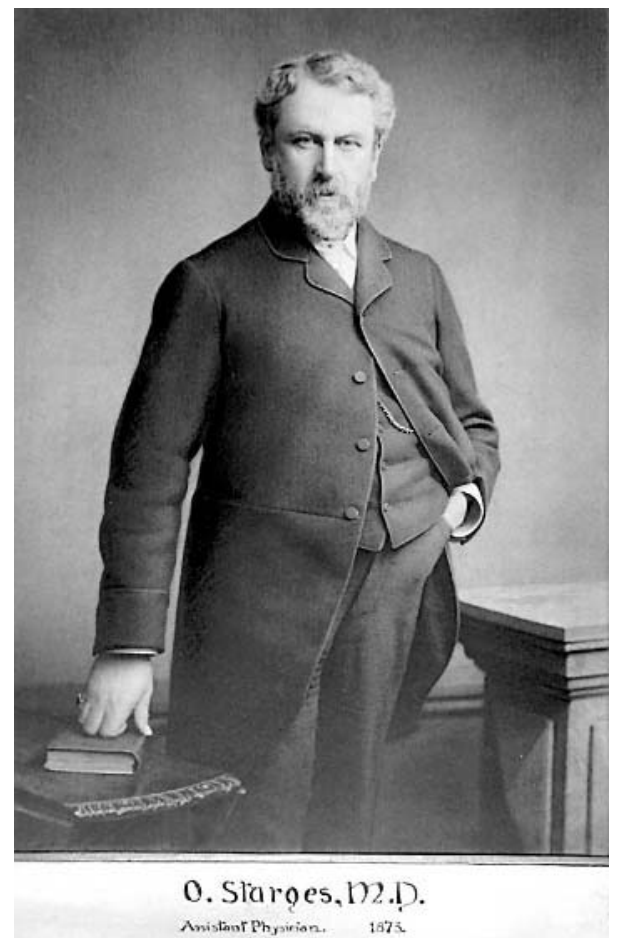

Figure 2 Octavius Sturges (1833-1894). The photograph was kindly provided by the Museum and Archives of the Great Ormond Street Hospital, London.

also by Charles West (founder physician of GOS), ${ }^{17}$ and subsequently by Osler, who stated that "the second hemidecade contains the greatest number of cases in males, and the third the greatest number in females" ${ }^{1}{ }^{1}$ In the majority of the 20th century studies, female preponderance is evident only in children over 10 years of age. ${ }^{16}{ }^{18}$ These observations suggest a role for oestrogen in SC expression. Supporting this view, oral contraceptives and pregnancy can cause relapses of disease. ${ }^{19}$

Ten per cent of the 1548 patients were subsequently admitted with a relapse of chorea. Given that relapse admissions had a negative impact on the hospital cure rate, this rate might underestimate the actual relapse incidence in the general population of patients.

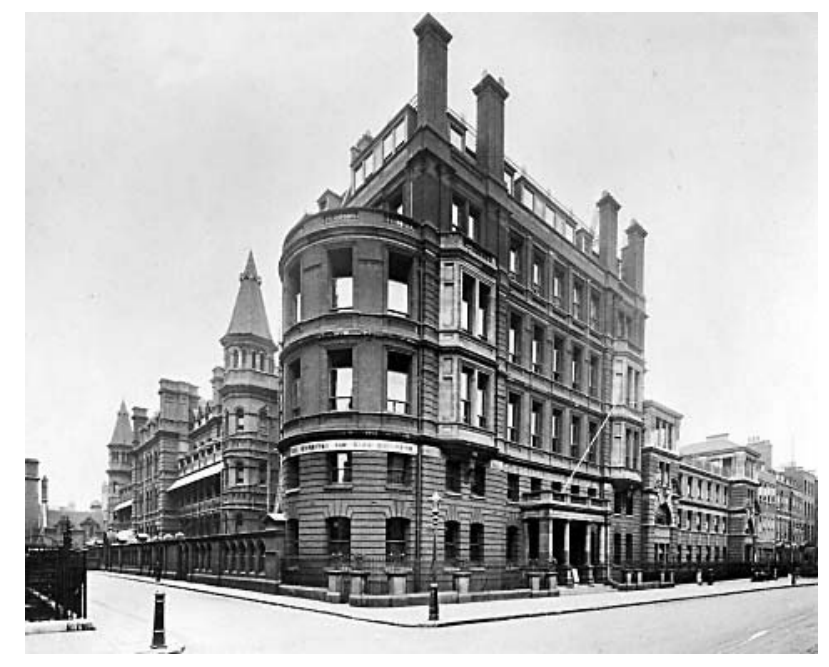

Figure 3 The Hospital for Sick Children (Great Ormond Street) in 1910. The photograph was kindly provided by the Museum and Archives of the Great Ormond Street Hospital, London. 


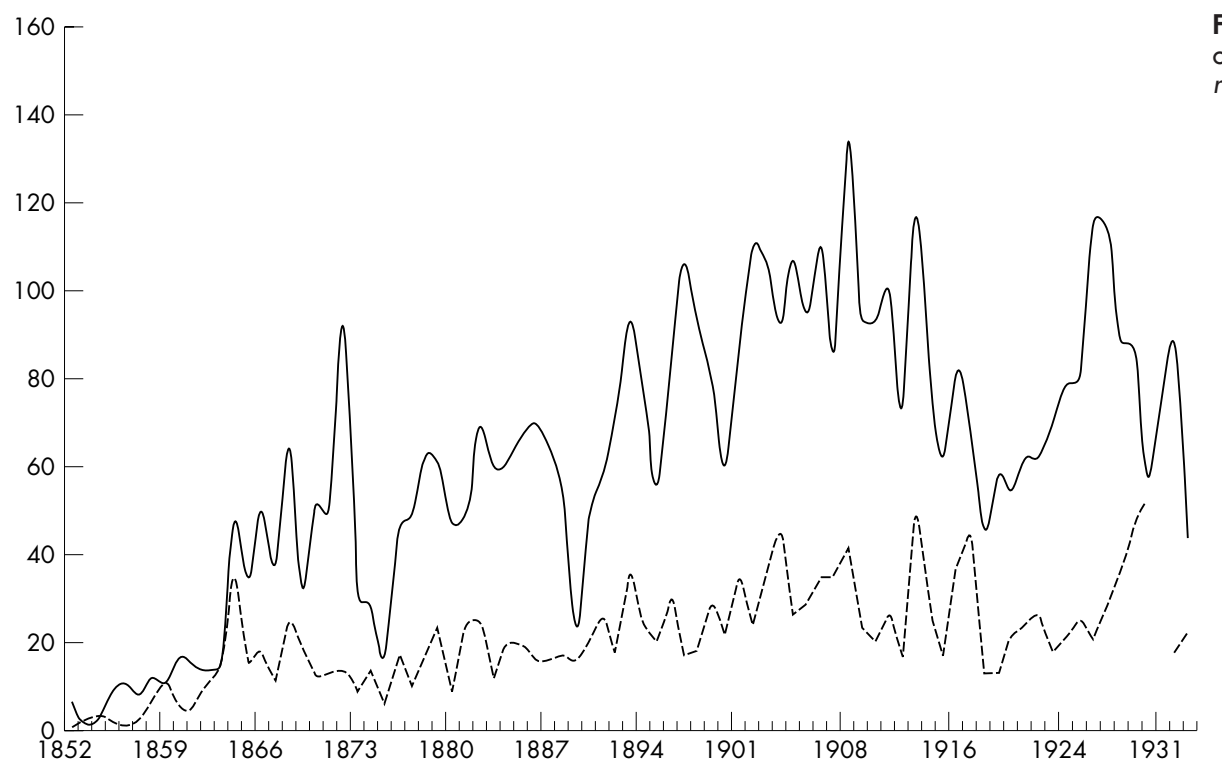

Figure 4 Yearly number of admissions of patients with chorea (solid line) and rheumatism (broken line).

\section{SELECTION OF CLINICAL NOTES Patient 1 (consultant WB Cheadle)}

Male, age 7 years and 9 months; admitted on March 18th 1890.

Was well until about six weeks ago, when he complained of pain in his legs and hands, which were pronounced to be rheumatic fever. Was kept in bed for a fortnight and three days later his hands were noticed to be twitching, the right hand being the worst; his mouth, and his legs were also similarly affected. He has been restless at night for three or four days, but when asleep there is no twitching. Father has had rheumatism and has "displacement of the heart". A brother has had St Vitus's Dance and rheumatism and heartweak; another brother St Vitus's Dance. A mother's stepsister had rheumatic fever and St Vitus's Dance.

The patient is continually moving the arms about, twitching his mouth in various directions, and shrugging his shoulders. The legs are to a less extent affected. The right side of the body seems most affected. When told to grasp the hand he is unable to give more than a spasmodic grasp and then looses it [while] the hand wanders round the object making ineffective attempts to hold it as constantly supinating and pronating the forearm. Tongue cannot be kept protruded. Muscles of expression act spasmodically; talks with difficulty and jerkily. Sphincters do not act properly either bladder or anal. General intelligence seems rather low; rather emotional. Joints not swollen, but ankles are painful.

Heart sounds: at apex the first sound is replaced by a loud rather rough murmur. From the apex the systolic murmur can be traced up to the aortic and pulmonary cartilages. After the first two days the patient became much quieter, could feed himself, and could drink without spilling his milk. The movements of his arms have almost ceased, the right arm twitching occasionally, and he stammers and hesitates in talking. Discharged on April 5th.

Diagnosis: Chorea. Endocarditis.

This patient is a "typical case" of SC, manifesting the predominant features of RF-that is, arthritis, carditis, and chorea. In his diagnostic "algorithm", ${ }^{20}$ Cheadle identified the common elements of the rheumatic syndrome ("endocarditis, pericarditis, pleurisy, tonsillitis, exudative erythema, chorea, subcutaneous nodules"), claiming that each of them was separate and that they could appear together in different "phases in the rheumatic process". Each of these elements, apart from subcutaneous nodules, could have other causes; the association of chorea with one or more rheumatic features became the distinctive characteristic of SC. Contemporary statistics validated Cheadle's conclusions: $26 \%$ of the British choreic patients had an acute or subacute rheumatic arthritis preceding chorea, $32 \%$ had a structural cardiac lesion (most frequently a purely mitral disease, as likely in patient 1), and 30\% had an already underlying cardiopathy at the time of the first choreic attack. ${ }^{12}$

In a British population based survey of $1887,{ }^{12}$ a rheumatic family history was reported in $45 \%$ of the choreic population, twice as many as reported (26\%) in the largest survey of the 20th century. ${ }^{21}$ Cheadle considered family history a useful diagnostic element, recommending a careful cross-examination of relatives to avoid false negative family history reports by the proband.$^{20}$ A family history of RF remains a useful indicator of post-streptococcal aetiology in the context of movement disorders. ${ }^{18} 22$

\section{Patient 2 (consultant $O$ Sturges)}

Female, age 10 years and 11 months; admitted on April 18th, 1890.

Last November, she had a bad throat and lumps in the neck. Since then she complained of pain in the legs at times, and was soon tired; she made faces; mother thought she was mimicking another girl at the school.

April 13th. She said she could not keep her hand in any position. She let things fall. Mother thinks the right hand is worse and the right leg is good. Three/four weeks ago speech indistinct. Patient has lost power in her limbs, especially the last 20 days. Patient's disposition has altered, she became silly and sullen from being bright and cheerful. Has had difficulty in doing her sums lately and has been kept in. Since Easter pain in right knee. Mother had rheumatic fever. A sister suffers with tonsils. Father had rheumatic fever when quite young. 


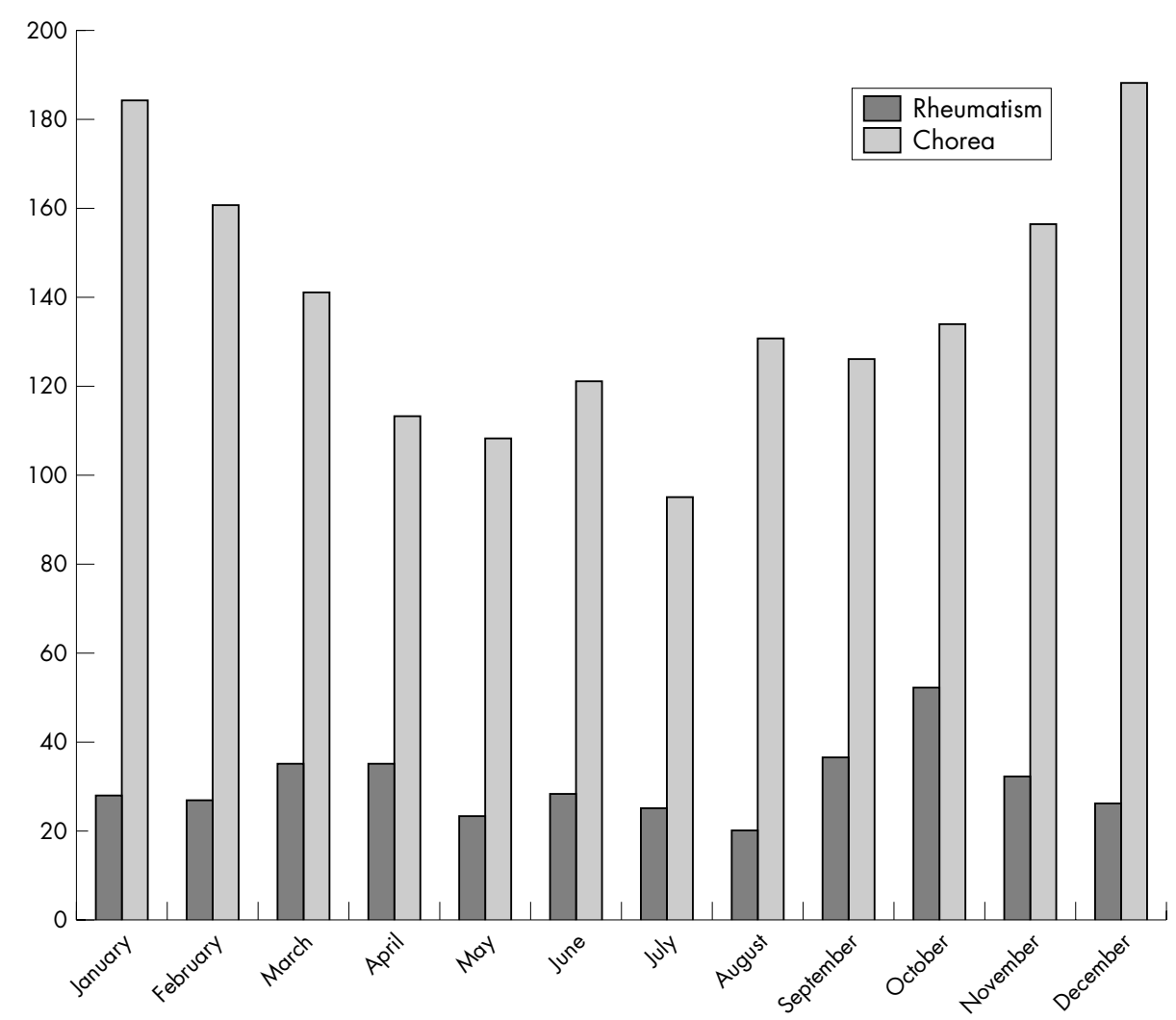

Figure 5 Monthly distribution of the admissions of chorea and rheumatism, related to the period 1852-95.

Intelligent, emotional, memory good. Before she says any word there is considerable smacking of lips.

Constant extensive movements of both arms, rather more extensive in right hand. Grip distinctly better on the left. In the face, movements are chiefly about the mouth, but also in eyes. Tongue protruded with difficulty, though frequently spontaneously. Constant clicking noise produced by action of tongue on palate.

Discharged on May 22nd.

Diagnosis: Chorea. Morbus cordis.

Frequently, as in this patient, the onset of chorea is in one limb, with subsequent generalisation. ${ }^{23}$ Patient 2 was thought by her mother to make faces and imitate another girl at school. A historical summary reported that a child with SC is punished three times before the diagnosis is made: "once for general fidgetiness, once for breaking crockery, and once for making faces at his grandmother". ${ }^{24}$ Likewise, the clumsy gait, the frequent dropping and spilling things, especially during meals, and the awkwardness in the fine movements of the hands are clearly reported in these cases. Patients 1 and 2 provide an example of the milkmaid's grip, defined as the inability to sustain a tetanic contraction, secondarily to hypotonia and involuntary movements. ${ }^{23}$

Motor impersistence of the tongue was also reported, in the form of unsustained tongue protrusion. The explosive bursts of inarticulated speech, the so-called Sydenham's speech, ${ }^{16}$ were often referred in these cases as "jerky" speech, but difficulty in starting speaking, stammering, or even indistinct speech were also described.

\section{FINAL COMMENTARY}

The GOS paediatricians in the second half of the 19th century were able to define important characteristics of disease, namely the association with arthritis, carditis, and a family history of RF. The progress in the clinical examination of the heart, driven by the introduction of the stethoscope in 1816 by Laennec, ${ }^{10}$ helped physicians in putting together the elements of the rheumatic disease, and isolating SC from the "nosological pot" that the term chorea represented in that period. This became fundamental for the identification of its correct aetiology, although its pathophysiology is still a matter of debate. ${ }^{25}{ }^{26}$ The ability of physicians to correctly diagnose chorea is witnessed by the similarity of demographic data between the observed period and nowadays.

GOS case notes do not report the full spectrum of psychiatric comorbidities recently described in SC (mainly, obsessive-compulsive behaviour and attention deficit), due probably to the more recent understanding of these behavioural disturbances. Nevertheless, the introduction of a "statistically averaging" approach to the definition of new clinical syndromes, as theorised by Cheadle's "algorithms", proves that the institution of paediatric hospitals in Great Britain since 1852 greatly increased the availability of large, epidemiologically relevant clinical series.

\section{ACKNOWLEDGEMENTS}

We are indebted to Nicholas Baldwin for his precious assistance at the Museum and Archives of the Great Ormond Street Hospital, London. We would like to acknowledge the European Union for supporting Dr Davide Martino through a Marie Curie Training Fellowship.

\section{Authors' affiliations}

D Martino, A J Church, G Giovannoni, Department of Neuroinflammation, Institute of Neurology, University College Medical School, London, UK

K P Bhatia, Sobell Department of Motor Neurosciences and Movement Disorders, Institute of Neurology, University College Medical School, London, UK 
A Tanner, Department of History, Kingston University, Kingston upon Thames, UK

G Defazio, Department of Neurological and Psychiatric Sciences, University of Bari, Italy

R C Dale, Neurosciences Unit, Great Ormond Street Hospital and Institute of Child Health, London, UK

Competing interests: none declared

\section{REFERENCES}

1 Osler W. On chorea and choreiform affections. London: HK Lewis \& Company, 1894.

2 Special Writing Group of the Committee on Rheumatic Fever, Endocarditis, and Kawasaki Disease of the Council on Cardiovascular Disease in the Young of the American Heart Association. Guidelines for the diagnosis of rheumatic fever: Jones criteria, 1992 update. JAMA 1992;268:2069-73.

3 Bright R. Cases of spasmodic disease accompanying affections of the pericardium. Trans Med-Chir Soc London 1838;22:1-19.

4 Bouteille EM. Traite de la Choree, ou Danse de St Guy. Paris: Vincard, 1810.

5 Roger H. Recherches cliniques sur la choree, sur le rheumatisme et sur les maladies du coeur chez les enfants. Arch Gen Med 1866;2:641-65.

6 Trousseau A, Cormack JR, Bazire PV, eds. Lectures on clinical medicine, 3rd edn. Philadelphia: Lindsay \& Blakiston, 1873.

7 Bright R. Reports of medical cases selected with a view of illustrating the symptoms and cure of diseases by reference to morbid anatomy. London: Longman, 1831.

8 See G. De la choree. Mem Acad Med (Paris) 1850;15:374.

9 Sandras CMS. Traite' Pratique des Maladies Nerveuses, I-II. Paris: GermerBailliere, 1851.

10 English PC. Emergence of rheumatic fever in the nineteenth century. In: Rosenberg C, Golden J, eds. Framing disease: studies in cultural history. New Brunswick, NJ: Rutgers University Press, 1991:20-32.
11 Annual Reports of The Hospital for Sick Children, Great Ormond Street, London, and Cromwell House, Highgate. London: Folkard R \& Sons (Vol. 1852 to Vol. 1936).

12 Mackenzie S. Reports of the Collective Investigation Committee of the British Medical Association. Report on Inquiry No. II, Chorea. BMJ 1887;1:425-36.

13 Waterhouse R. Children in hospital: a hundred years of child care in Birmingham. London: Hutchinson, 1962

14 Lomax EMR. Small and special: the development of hospitals for children in Victorian Britain. Medical History 1996;(suppl 16) (London: Wellcome Institute for the History of Medicine)

15 Jacobsen $\mathrm{E}$. Rheumatic fever with chorea minor: a clinical study with special reference to the prognosis. Acta Paediatr (Uppsala) 1946;33(suppl 7): 1-222

16 Thiebaut F. Sydenham's chorea. In: Vinken PJ, Bruyn GW, eds. Handbook of. Clinical Neurology: Diseases of the Basal Ganglia, Vol.6. Amsterdam: North Holland, 1968:409-34.

17 West C. Lectures on the diseases of infancy and childhood, 5th edn. London, 1865:203-31.

18 Nausieda PA, Grossman BJ, Koller WC, et al. Sydenham chorea: an update. Neurology 1980;30:331-4.

19 Nausieda PA, Koller WC, Weiner WJ, et al. Chorea induced by oral contraceptives. Neurology 1979;29:1605-9.

20 Cheadle WB. Various manifestations of the rheumatic state. Lecture II. Lancet 1889:1:871-7.

21 Aron AM, Freeman JM, Carter S. The natural history of Sydenham's chorea. Am J Med 1965;28:83-95.

22 Dale RC, Heyman I, Surtees RAH, et al. Dyskinesias and associated psychiatric disorders following streptococcal infections. Arch Dis Child 2004:89:604-10.

23 Swedo SE. Sydenham's chorea: a model for childhood autoimmune neuropsychiatric disorders. JAMA 1994;272:1788-91.

24 Wilson SK. Neurology, 2nd edn. New York: Hafner Press, 1969

25 Dale RC. Autoimmunity and the basal ganglia: new insights into old diseases. QJM 2003:96:183-91.

26 Kirvan CA, Swedo SE, Heuser JS, et al. Mimicry and autoantibody-mediated neuronal cell signaling in Sydenham chorea. Nat Med 2003;9:914-20.

\section{bmjupdates+}

bmiupdates+ is a unique and free alerting service, designed to keep you up to date with the medical literature that is truly important to your practice.

bmjupdates+ will alert you to important new research and will provide you with the best new evidence concerning important advances in health care, tailored to your medical interests and time demands.

Where does the information come from?

bmiupdates+ applies an expert critical appraisal filter to over 100 top medical journals A panel of over 2000 physicians find the few 'must read' studies for each area of clinical interest

Sign up to receive your tailored email alerts, searching access and more...

www.bmjupdates.com 